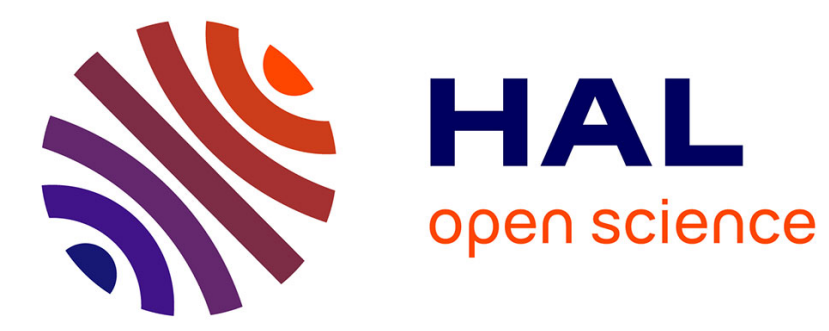

\title{
Mixture Homogeneity and its Influence on the Sintering and Magnetic Performance of MnZn-Ferrites
}

\author{
V. Zaspalis, R. Mauczok, J. Boerekamp, M. Kolenbrander
}

\section{To cite this version:}

V. Zaspalis, R. Mauczok, J. Boerekamp, M. Kolenbrander. Mixture Homogeneity and its Influence on the Sintering and Magnetic Performance of MnZn-Ferrites. Journal de Physique IV Proceedings, 1997, 07 (C1), pp.C1-75-C1-76. 10.1051/jp4:1997118 . jpa-00254828

\section{HAL Id: jpa-00254828 https://hal.science/jpa-00254828}

Submitted on 1 Jan 1997

HAL is a multi-disciplinary open access archive for the deposit and dissemination of scientific research documents, whether they are published or not. The documents may come from teaching and research institutions in France or abroad, or from public or private research centers.
L'archive ouverte pluridisciplinaire HAL, est destinée au dépôt et à la diffusion de documents scientifiques de niveau recherche, publiés ou non, émanant des établissements d'enseignement et de recherche français ou étrangers, des laboratoires publics ou privés. 


\title{
Mixture Homogeneity and its Influence on the Sintering and Magnetic Performance of MnZn-Ferrites
}

\author{
V.T. Zaspalis, R. Mauczok, J. Boerekamp* and M. Kolenbrander*
}

Philips Research Laboratories, P.O. Box 1980, 52021 Aachen, Germany

* Philips Components, BG Magnetic Products, P.O. Box 218, 5600 Eindhoven, The Netherlands

\begin{abstract}
The homogeneity of the green mixture, during the manufacturing of MnZn-Ferrites, is a process parameter which can be measured in a quantitative way. This parameter, depends on the morphological properties of the raw materials and determines the final power losses of the sintered products. By influencing this parameter with appropriate techniques good magnetic performances can also be achieved without the usage of extra sintering dopants.
\end{abstract}

\section{INTRODUCTION}

In previous works [e.g. ref.1] a correlation has been found between the low (ca.100kHz) and medium (ca.500kHz) frequency power losses of soft Mnzn-Ferrites and the homogeneity of the distribution of the main composition elements in their matrix. This correlation can be extended backwards to the beginning of the manufacturing process up to the homogeneity of the green mixture which consists of the mixed oxides (or carbonates) of the elements.

1.1 Definition and measurement of the green mixture homogeneity: The green mixture homogeneity Index for Fe or Mn have been defined as the reciprocal of the area under the lines shown in Figure 1 . Those lines represent the dependency of the elemental composition as a function of sampling size (e.g. every mixture is inhomogeneous if the sampling size is small enough). The compositional analysis have been made by means of an Electron Microscope (SEM) with Energy Dispersive Analysis of X-rays (EDAX). The sampling size has been varied by simply varying the size of the area to be analyzed. The homogeneity Index can then be represented by the formula:

$I N D E X=\left[\int_{L_{1}}^{L_{2} \rightarrow 0} \operatorname{var}(L)_{(F e, M n)} d L\right]^{-1}$

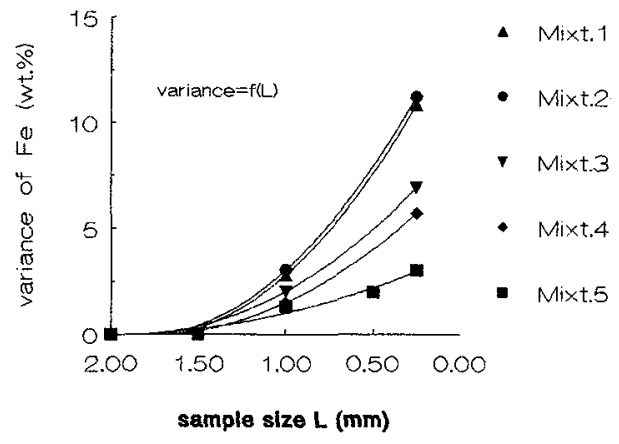

Figure 1: Ten measurement standard deviation of $F e$ as a function of sampling size, for green mixtures containing various iron oxides. 


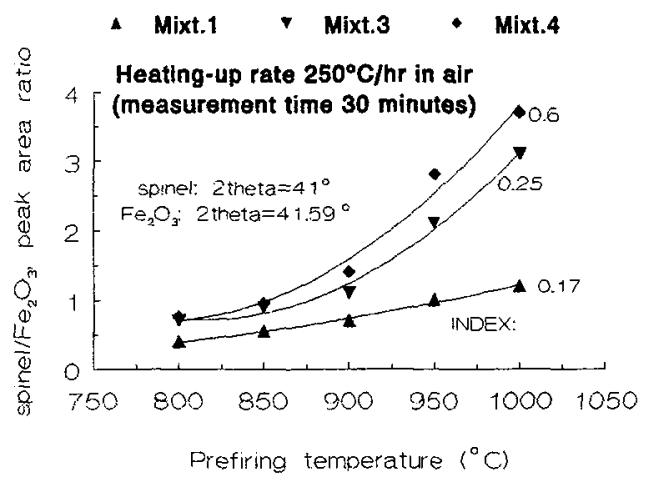

Figure 2: In situ $X$-ray diffraction during prefiring of mixtures with various Indexes.

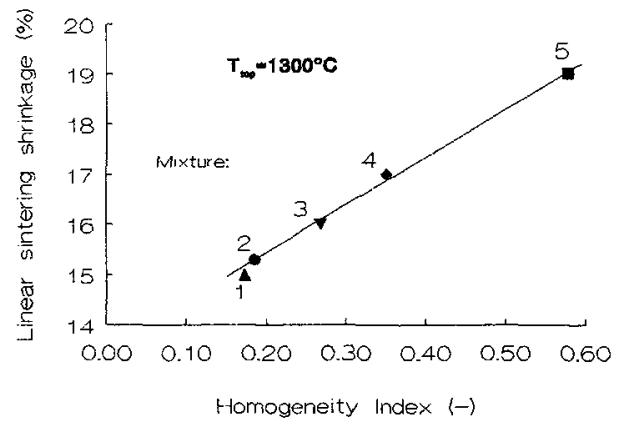

Figure 3: Sintering shrinkage as a function of the homogeneity Index.

where in equation (1) $L_{1}$ is the initial sampling size (chosen to be large enough), and $L_{2}$ is the final sampling size (small enough).

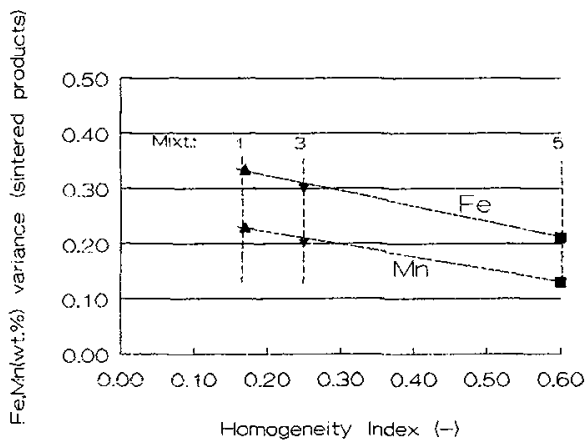

Figure 4: Variance of $F e$ and $M n$ elemental mol.: content in the matrix of sintered products ( 25 measurements)

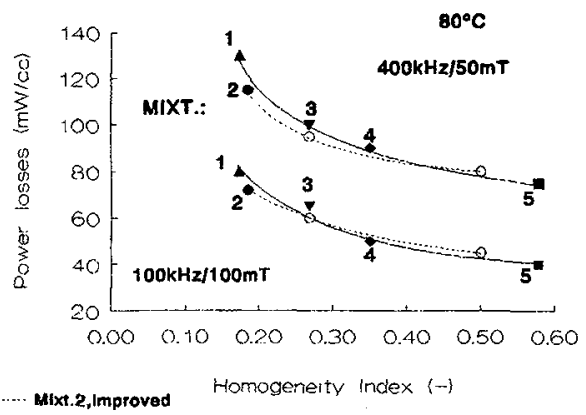

Figure 5: Power losses for products as a function of the homogeneity Index (various or identical raw-materials)

\section{RESULTS AND DISCUSSION}

In Figures 2 the hematite/spinel ratio is shown as measured in situ during prefiring and as a function of the previously defined Index. In Figure 3 the sintering shrinkage is shown. In Figure 4 the homogeneity distribution of the elements in the matrix of the sintered products is shown as a function of the homogeneity Index. The magnetic properties are shown in Figure 5 for microstructures with comparable densities and grain sizes.

It is clear from the above Figures that the homogeneity of the green mixture influences in a systematic way: i) the reaction chemistry through the prefiring step, ii) the obtained linear shrinkage after sintering iii) the homogeneity of the elemental distribution in the matrix of the sintered products and $i v)$ the magnetic performance of the products. It is obvious that the right raw-material and homogeneity Index choice can enable the manufacturing of products with good magnetic properties even by the standard processing routes.

\section{References}

[1] Nomura T., Micro- and nano-structure-property relationships in soft ferrites, Proceedings ICF6, p.809, Tokyo, Japan, 1992 